\title{
Modos de Vida da População em Situação de Rua: a produção acadêmica no Espírito Santo
}

\author{
Livelihoods of the homeless population: the academic production \\ in Espírito Santo.
}

Diego Arthur Lime Pinheiro; Ana Lúcia Coelho Heckert; Lucas Xavier Silva; Lucas de Souza Lopes

Universidade Estadual de Feira de Santana; Universidade Federal do Espírito Santo

\section{RESUMO:}

Este artigo se propõe a estudar como os modos de vida da população em situação de rua têm sido abordados no âmbito das produções acadêmicas. Neste trabalho, focalizamos o mapeamento da produção de dissertações e teses defendidas no Brasil no período de 2010 a 2016, destacando a produção acadêmica realizada no Estado do Espírito Santo. A metodologia utilizada para produzir os dados foi o Estado do Conhecimento, usando como procedimento a pesquisa bibliográfica. A partir do material levantado, efetuamos uma análise do modo como a população de rua configura campos problemáticos nessas produções. O resultado apontou a reduzida produção de conhecimento acadêmico acerca dos modos de vida deste grupo populacional, o que tem interferido negativamente na elaboração de políticas públicas e na formação de profissionais que atuam com este segmento populacional. Espera-se fornecer subsídios para ampliação da produção de conhecimentos e das redes de garantia de direitos no Espírito Santo.

Palavras-chave: população em situação de rua, políticas públicas, estado do conhecimento.

\section{ABSTRACT:}

This article proposes to study how the livelihoods of the street population have been approached in the scope of academic productions. In this work, we focus the mapping of the production of dissertations and theses defended in Brazil from 2010 to 2016, highlighting the academic production carried out in the State of Espírito Santo. The methodology used to produce the data was the Knowledge State, using as a procedure the bibliographic research. From the material collected, we analyze the way the street population sets up problematic fields in these productions. The result pointed to the reduced production of academic knowledge about the livelihoods of this population group, which has negatively interfered in the elaboration of public policies and the training of professionals that work with this population segment. It is hoped to provide subsidies for expanding knowledge production and guarantee networks in Espírito Santo.

Key-words: population in street situation, public policies, state of knowledge. 
A população em situação de rua, segundo uma terminologia mais atual (VIEIRA, BEZERRA \& ROSA, 2004), se apresenta como um problema que historicamente tem feito parte da paisagem das cidades brasileiras, sendo que as formas de gerir diretamente esta problemática estão atreladas às políticas elaboradas para a organização do espaço urbano. $\mathrm{O}$ esvaziamento dos espaços públicos e a acelerada privatização dos espaços da cidade têm contribuído para intensificar processos de segregação e isolamento sociais. A cidade tem sido organizada de forma a impedir/reduzir as misturas e a circulação, opondo casa e rua, público e privado, centro e periferia. Os mais pobres vêm sendo empurrados para espaços de moradia nas periferias urbanas ou ocupam as ruas da cidade e se constituem como uma 'ameaça à segurança', à 'ordem da polis' (KUNZ, HECKERT \& CARVALHO, 2013).

A experiência da vida nas ruas ainda é pouco conhecida, ainda são reduzidos os estudos acerca deste tema que de fato dialoguem com as singularidades que a vida na rua expressa. $\mathrm{E}$ isso tem interferido negativamente no que se refere ao modo como este grupo social é abordado pela sociedade, na formação dos profissionais que atuam nas políticas sociais, como também na elaboração e implementação de políticas públicas voltadas a este segmento social. Ao mesmo tempo, tem recrudescido a violência contra este segmento social e a moralização de seus modos de vida. Nos estudos de Kunz (2012) e nas análises efetuadas por Kunz, Heckert e Carvalho (2014), aponta-se que as produções acadêmicas acerca da população em situação de rua têm focalizado questões de ordem econômica e de fragilização de vínculos familiares, mas poucos são os estudos, como os de Kasper (2006) e de Lima (1998), que se dedicaram a uma atenção cuidadosa acerca da vida cotidiana deste grupo social, de seus saberes e práticas.

A população de rua é um grupo heterogêneo, constituído em sua maioria por negros e por sujeitos com reduzida vivência escolar (BRASIL, 2009). Seu cotidiano de vida é marcado por intensa mobilidade que se efetua ou em função das redes de solidariedade criadas nas ruas ou em função das ações de repressão e de violência das quais são alvos constantes. Estudos como os de Escorel (2000), Bessa (2009), Rosa (1995), e as últimas estimativas divulgadas pelo Instituto de Pesquisa Econômica Aplicada (IPEA, 2016) apontam que o quantitativo de pessoas em situação de rua tem aumentado nos últimos anos. Contudo, poucos são os municípios que têm construído uma rede de políticas públicas que viabilize o atendimento das demandas deste grupo social. Em boa parte das cidades brasileiras, as ações do poder público têm se reduzido ou a ações repressoras de retirada das ruas ou a ações meramente assistenciais. 
Esta parcela da população lida cotidianamente com vários estigmas e preconceitos, dentre eles, atualmente, o de que são responsáveis pelo incremento do uso de drogas como o crack nas ruas das capitais brasileiras. Como expressão disso, foi possível acompanhar ao longo do ano de 2017 como em São Paulo a violência marcou (e ainda marca) a gestão municipal, com retirada dos moradores das ruas com jatos de água, proibição de entrega de alimentos à população de rua, retirada de seus pertences das vias públicas, dentre outras práticas violentas. Não muito diferente, no Espírito Santo a violência também tem se expressado e parte da população domiciliada tem usado a mídia para pedir a retirada da população de rua das vias públicas. Contudo, asseveramos que a vida na rua é complexa e nenhuma análise linear consegue abarcar sua heterogeneidade. No que se refere ao Espírito Santo, salvo dados levantados pelo Projeto Abordagem de Rua da Secretaria Municipal de Assistência Social (SEAS) do município de Vitória/ES, a escassez de produção acadêmica acerca desta parcela da população no Estado do Espírito Santo tem colaborado para o não desenvolvimento de estratégias de intervenção que se contraponham à forte violação de seus direitos.

Diante desse cenário social, esta pesquisa apresenta-se como um desdobramento do Projeto de Extensão "Andarilhos: apoio às movimentações sociais e às políticas públicas para a população em situação de rua", vinculado ao Departamento de Psicologia da Universidade Federal do Espírito Santo.

Criado em 2011 a partir de demandas dos estudantes do curso de Psicologia da UFES, o projeto de extensão desenvolveu atividades que propõem apoiar e fomentar políticas públicas voltadas à população em situação de rua. Encerrado em 2017, o projeto visava acompanhar a multiplicidade das relações tecidas entre essa população e os demais moradores da cidade de Vitória/ES. As ações do projeto se basearam nas vivências adquiridas na ida à rua e no diálogo com a própria população em situação de rua (HECKERT, PINHEIRO \& SABINO, 2016), cartografando suas demandas e os modos como a vida pode se constituir na ocupação de espaços públicos, traçando estratégias para além e aquém dos mecanismos de precarização que incidem sobre ela constantemente (PINHEIRO, 2017). Esta experiência de diálogo com a população em situação de rua provocou uma diversidade de questões que nos demandou um mapeamento da produção de conhecimentos e a criação de ferramentas de trabalho que nos permitissem compreender e analisar os modos de vida da população em situação de rua, efetuando um deslocamento nas concepções do habitar. 
Nesse sentido, a presente pesquisa visou, a partir das vivências na extensão, impulsionar a construção teórico-metodológica a respeito das questões que atravessam a vida na rua. Neste estudo, consideramos que os processos de habitar a rua não estão necessariamente atrelados à ideia de fracasso, de inadequação e/ou desajustamento com relação a uma vida estabelecida dentro dos moldes usuais de moradia e trabalho. Diferentemente, salientamos com Kasper (2006: 7) que "viver na rua constitui uma condição, isto é, um conjunto de constrangimentos e de recursos a partir dos quais devem ser construídas as bases materiais e simbólicas da existência”. Dessa maneira, chamamos atenção para a necessidade de usarmos um conceito de habitar que não se reduza à forma-casa e ao seu conjunto de funções. Para Kasper (2006: 25), o habitar envolve muitos verbos: apropriar-se de um espaço; instalar-se adequando o espaço; incorporar o ambiente. O desafio, segundo o autor, é caracterizar o processo do habitar sem subordiná-lo ao espaço da casa. A vivência da extensão tem mostrado esta potência do habitar presente nos modos de vida da população de rua, afirmando grupos e sujeitos capazes de relações únicas com os espaços urbanos (PINHEIRO, 2017).

\section{Método}

Nossa proposta teve como objetivo estudar as maneiras como as pesquisas têm problematizado a chamada população em situação de rua e seus modos de vida. Para tal, delimitamos a primeira etapa deste estudo na elaboração do estado do conhecimento (ROMANOWSKI \& ENS. 2006) acerca da população em situação de rua, mapeando produções acadêmicas efetuadas sob a forma de dissertações e teses elaboradas no Espírito Santo entre os anos de 2010 e 2026 e que, no mesmo período, focalizaram a população em situação de rua como tema de suas pesquisas. As pesquisas que utilizam o Estado do Conhecimento como instrumento de produção de dados permitem não apenas compreender o conhecimento elaborado e sistematizado sobre determinado objeto de pesquisa, como também viabiliza tecermos um levantamento "[...] analítico e crítico da produção acadêmica sobre determinado tema" (TEIXEIRA, 2006: 60). Consideramos que o inventário da produção acadêmica sobre a população em situação de rua pode nos indicar não apenas lacunas importantes, como também sinalizar os modos de vida que estão sendo engendrados nestas produções por meio dos temas tratados e das perspectivas de teórico-metodológicas adotadas. Consideramos que esta sistematização pode subsidiar, posteriormente, o aprofundamento de estudos relativos à 
população de rua, viabilizando a construção de percursos mais amplos de pesquisa acerca desta temática.

Este período foi delimitado em função de que nos últimos 06 anos (2010-2016) ampliaram-se as ações dos movimentos nacionais de população em situação de rua (dentre os quais destacamos o Movimento Nacional de Meninos e Meninas de Rua - MNMMR/1985, as chamadas Pastorais do Povo de Rua - criadas em algumas cidades do país a partir da década de 1980, o Movimento Nacional de Catadores de Materiais Recicláveis - MNCR/2001, o Movimento Nacional da População de Rua - MNPR/2005) e, principalmente, as movimentações que estão para além e aquém dos movimentos sociais ditos organizados, denunciando violações de direitos sociais e demandando políticas públicas. Assim, este mapeamento pode trazer subsídios para analisarmos como têm repercutido na pesquisa acadêmica as movimentações da população de rua por acesso às políticas públicas.

Após a delimitação do período, o estudo teve como metodologia a revisão bibliográfica em sua segunda etapa de desenvolvimento. Segundo Gil (2008), esse método possibilita ampliar ou aprofundar com detalhes o problema de pesquisa, além de criar condições para apontar questões que necessitem de futuras investigações. Os dados que apresentaremos a seguir foram obtidos a partir de uma leitura exploratória de publicações acadêmicas. A leitura exploratória se caracteriza como uma leitura preliminar do material bibliográfico para investigar e verificar se o tema do material coletado faz interseção com o tema desta pesquisa.

A fonte de referência para o levantamento das dissertações e teses vinculadas ao tema e defendidas entre os anos de 2010 e 2016 foi o banco de dados da CAPES, acrescido dos sítios dos Programas de Pós-Graduação existentes no Espírito Santo, onde realizamos a busca com os seguintes descritores: população em situação de rua; políticas públicas; vida nas ruas; direitos sociais. Essas palavras-chave, no entanto, produziram resultados imprecisos e não contemplaram diretamente o foco desta pesquisa que é a população em situação de rua. Dessa maneira, delimitamos o estudo proposto aos descritores: população em situação de rua e população de rua, utilizando-os nas seguintes áreas do conhecimento: ciências humanas, ciências sociais aplicadas e ciências da saúde.

Após a leitura dos resumos dos trabalhos, efetuamos a leitura exploratória de cada obra revisada, elaborando e utilizando na sequência fichas documentais para o registro e transcrição dos dados obtidos (GIL, 2008). Posteriormente, efetuamos a leitura analítica a partir da qual foi possível tecer direções e discussões acerca do que se tem produzido sobre a população em 
situação de rua no período delimitado. Ficamos atentos também para verificar temas emergentes nas pesquisas realizadas e as lacunas existentes acerca da população em situação de rua. Outro destaque dado foi às perspectivas metodológicas utilizadas nestas produções acadêmicas.

A elaboração do estado do conhecimento nos ajudou a compreender a sistematização da produção de saberes-fazeres acerca da população de rua no período delimitado, conforme apontaram os estudos de Ferreira (2002). Consideramos que o inventário da produção acadêmica sobre a população em situação de rua pode nos indicar não apenas lacunas importantes, como também sinalizar os modos de vida que estão sendo engendrados nestas produções por meio dos temas tratados e das perspectivas de análise adotadas. Por fim, conforme indicam os trabalhos que utilizam o Estado da Arte e o Estado do Conhecimento como metodologias de pesquisa (FERREIRA, 2002), ressaltamos que a pesquisa proposta pode contribuir na realização de novas pesquisas e também na elaboração de políticas públicas destinadas a este segmento social.

\section{Resultados}

A partir da leitura exploratória do material encontrado apresentaremos a seguir os dados encontrados. Inicialmente apresentaremos os dados gerais para, posteriormente, focalizarmos o escopo das pesquisas realizadas no Espírito Santo.

No período de 2010 a 2016 foram encontrados 129 trabalhos no banco de teses e dissertações da CAPES para os descritores "população de rua" e "população em situação de rua", sendo deste total 106 dissertações de mestrado e 23 teses de doutorado.

\section{Regiões de Origem}

$\mathrm{Na}$ classificação dos trabalhos por regiões de origem é possível notar que a maior produção se concentra na região Sudeste, contabilizando um total de 73 trabalhos entre teses e dissertações. Dentre os 73, apenas 09 dissertações são localizadas no Espírito Santo. Na região Nordeste foram encontrados 20 trabalhos, seguido por 19 na região Sul. O número de trabalhos encontrados na região Centro-Oeste é de 15 trabalhos. Por fim, a região Norte é contemplada com apenas 02 trabalhos. 
290 Diego Arthur Lime Pinheiro; Ana Lúcia Coelho Heckert; Lucas Xavier Silva; Lucas de Souza Lopes.

\begin{tabular}{cc}
\hline Região & Número de trabalhos \\
\hline Sudeste & 73 \\
Nordeste & 20 \\
Sul & 19 \\
Centro Oeste & 15 \\
Norte & 02 \\
Total & 129
\end{tabular}

Tabela 1. Trabalhos distribuídos por região. Fonte: Capes

\section{Ano da publicação}

A tabela 2, apresentada abaixo, indica a distribuição dos trabalhos por ano. Podemos perceber que a distribuição dos trabalhos neste período teve pequena variação, destacando-se o crescimento no número de trabalhos defendidos que se manteve a partir do ano de 2014. No tocante aos trabalhos produzidos no Espírito Santo, não foram encontradas teses e dissertações com afiliação ao tema proposto no ano de 2010. Foram encontrados: 01 trabalho no ano de 2011, 01 em 2012, 01 em 2013, 01 em 2014, 03 em 2015 e 02 em 2016, destacando o reduzido número de trabalhos relacionados ao tema defendidos nos últimos seis anos no Estado.

\begin{tabular}{cc}
\hline Ano de Publicação & Número de trabalhos \\
\hline 2010 & 08 \\
2011 & 08 \\
2012 & 15 \\
2013 & 16 \\
2014 & 27 \\
2015 & 28 \\
2016 & 27 \\
Total & 129
\end{tabular}

Tabela 2. Trabalhos distribuídos por ano no Brasil. Fonte: Capes 


\section{Área de conhecimento}

A tabela 03 expressa a distribuição dos trabalhos pelas áreas de conhecimento pesquisadas na plataforma da CAPES, indicando a maior concentração de trabalhos na área de ciências humanas, seguida pela área de ciências socais e, por fim, a área de ciências da saúde.

\begin{tabular}{cc}
\hline Área de & Número de trabalhos \\
Conhecimento & \\
\hline Ciências Humanas & 66 \\
Ciências Sociais & 40 \\
Ciências da Saúde & 23 \\
Total & 129
\end{tabular}

Tabela 3. Trabalhos distribuídos por área de conhecimento em âmbito nacional. Fonte: Capes

No Espírito Santo, as dissertações encontradas foram todas defendidas na UFES, e estão assim distribuídas entre as três áreas de conhecimento destacadas: 06 em ciências humanas, 02 em ciências sociais e 01 em ciências da saúde. As dissertações foram apresentadas aos seguintes Programas de Pós-Graduação: Programa de Pós-Graduação em Política Social, com 02 dissertações, defendidas nos anos de 2014 e 2016 respectivamente; Programa de Psicologia, com 01 dissertação defendida no ano de 2015; Programa de Pós-Graduação em Psicologia Institucional, com 05 dissertações, sendo uma defendida no ano de 2012, uma no ano de 2013, duas no ano de 2015 e uma no ano de 2016; Programa de Pós-Graduação em Saúde Coletiva, com 01 dissertação defendida no ano de 2011.

\section{Discussão}

Como indicado anteriormente, a produção acadêmica em forma de dissertações e teses abarca o quantitativo de 129 trabalhos publicados em âmbito nacional no período entre os anos de 2010 e 2016. A maioria das pesquisas está situada na área de ciências humanas, abordando temas como acesso a redes de saúde e socioassistenciais, políticas de álcool e outras drogas, modos de vida nas ruas e garantia de direitos. A maioria dos estudos, no entanto, é permeada pela oposição entre a casa e a rua. Frequentemente, a vida na rua é apresentada em torno do que se chama de uma progressiva desvinculação com os modos da casa, com as relações familiares 
e comunitárias. Em outras palavras, a maioria desses estudos parte da perspectiva de que a vida na rua se constrói em função da fragilização ou interrupção de vínculos e pela ausência de moradia convencional, o que compeliria grupos e indivíduos a utilizarem as ruas como espaço de moradia e sustento.

Em muitos trabalhos, a casa não é considerada como um dos pontos na trajetória que as pessoas em situação de rua fazem ao transitarem pela cidade. As formas de relações sociais que escapam aos modos domiciliados, ou seja, tomando a casa como ponto de referência privilegiado na construção de modos de vida, são pouco apresentadas e valorizadas. Poucos trabalhos partem da fala direta de pessoas em situação de rua, sem a mediação de instituições e/ou serviços. São também poucos os trabalhos que partem das movimentações sociais deste grupo populacional em torno da construção de redes de garantias de direitos e de seu cotidiano nas ruas. Destacamos, assim, que as lutas realizadas pelos movimentos nacionais de população em situação de rua por acesso à moradia, à saúde, à educação, à alimentação, a direitos econômicos, e principalmente, por acesso à cidade repercutem de maneira ínfima na produção acadêmica.

Segundo entendemos, faz-se necessário que a produção acadêmica consiga acolher em seus trabalhos as movimentações sociais da população em situação de rua luta desde os lugares que tais movimentos ocupam na cidade. Em outras palavras, que o ato de se instalar nas praças, nas escadarias, nas ruas da cidade não impeça o exercício de determinada política da vida, que será acessada pela produção acadêmica quase que exclusivamente de forma perspectivada pelo aparato de Estado e pelos saberes constituídos. Isto é, um contato com a população de rua marcado pelo atravessamento por serviços públicos, pelas entrevistas com profissionais que atuam nesses serviços, e deixando de lado toda parcela dessa população que recusa a política de tais serviços, seus modos de funcionamento e mesmo aqueles que não têm acesso aos equipamentos públicos por qualquer motivo.

Tais análises perspectivadas pelas políticas de Estado e pelos saberes constituídos deslegitimam uma política da existência que faz do próprio deslocamento um território subjetivo (PINHEIRO, 2017). Neste sentido, podemos entender a rua enquanto campo político de tecedura de sensibilidades onde diversos enfrentamentos de forças podem nos indicar as desnaturalizações da vida precarizada, colocando em evidência a invenção das lutas cotidianas que se operam na ocupação dos espaços públicos da cidade. Dessa maneira, como espaço de embate político, as ruas são detonadoras de sentidos e de modos de categorização do humano. 
Ressaltamos que esse caráter de movimento, de acionar práticas, de interferir produzindo ou dissipando conflitos está pouco presente nos trabalhos encontrados no âmbito nacional.

No entanto, analisando a produção acadêmica produzida no Espírito Santo, é possível observar que a rua não é tratada exclusivamente como mero espaço de passagem por onde desfilam existências precarizadas. Diferentemente, em seus usos e contra-usos, nela concorrem práticas capazes de suscitar múltiplos sentidos para os processos do habitar, expressando ao mesmo tempo a mobilização de redes de generosidade e de coerção entre a população de rua e os demais atores dos espaços urbanos (KUNZ, 2012; KUNZ et al. 2014; CUNHA, 2015; MARINS, 2015; LOPES, 2015; GUARNIER, 2016; TIENGO, 2016).

Ainda que a maioria dos trabalhos no país estejam situados na área das ciências humanas, muitos abordam questões relativas à saúde pública, como tuberculose, saúde mental, o acesso aos serviços de saúde e o do chamado uso problemático de álcool e outras drogas (WANDEKOKEN, 2011). Mesmo com alguns trabalhos nesta área apresentando a população de rua como usuária de substâncias psicoativas ilícitas, o número de artigos abordando tal questão é irrisório. Ou seja, a afirmação de que a maioria da população de rua é dependente de drogas não está acompanhada de um número de pesquisas acadêmicas significativas que embasem tais afirmações.

Os trabalhos que tratam das políticas de saúde e das políticas socioassistenciais são atravessados por uma preocupação com a sistematização do atendimento e acompanhamento das pessoas em situação de rua (WANDEKOKEN, 2011; ARAÚJO, 2014). Essa necessidade específica de sistematização nas ditas abordagens e acompanhamentos muitas vezes ecoa noções de adestramento, de domesticação e de adequação da população de rua a modos de vida pautados na separação entre público e privado, entre o bom e o mau pobre, entre o lícito e o ilícito, entre aqueles que justificam os investimentos socais com base na adesão às propostas dos serviços e aqueles que não. O agravante aqui é que as redes de atenção em saúde e socioassistenciais frequentemente desconsideram em sua elaboração e implementação a política de deslocamento exercida pela população de rua na ocupação de territórios, contribuindo assim para precarizar a existência desse grupo social no tecido urbano (MACERATA, SOARES \& RAMOS, 2014; PINHEIRO, 2017).

Como podemos observar nos dados disponíveis, a produção de pesquisas acadêmicas está pautada em saberes que, historicamente, contribuíram para institucionalização da rua como espaço de intervenção em favor de certa noção de família, de sociabilidade e de trabalho. São 
poucos os trabalhos que indagam os lugares de saber onde se produziram, tornando-se insensíveis às provocações éticas e políticas que os modos de vida da população de rua colocam aos modelos da casa, dos chamados bons costumes, da higiene, da docilidade que se abateu sobre os corpos desde a modernidade e que procurou apagar seus rastros, suas histórias e seu cotidiano (CORBIN, 1987).

Consequentemente, a formação de profissionais para atuar junto deste segmento populacional é outro fator a ser evidenciado. Os profissionais de diversas áreas que fazem parte das equipes que atuam com a população em situação de rua, em áreas como a saúde, a educação, a psicologia e outras áreas afins, desconhecem os modos de viver deste segmento e pouco sabem lidar com suas demandas e problemas. O efeito deste processo são usuários insatisfeitos em função de uma metodologia de trabalho ineficaz, que não os inclui no processo de discussão e efetivação das políticas públicas, uma metodologia de trabalho que destoa dos modos de vida da população de rua (KUNZ, 2012).

Desde a modernidade, as populações que ocupam as ruas das cidades têm sido exaustivamente trabalhadas no âmbito das ciências humanas, das ciências sociais e da saúde como grupos sociais atrelados à ideia de fracasso, de inaptidão e de miséria sem riqueza virtual. Podemos dizer que essas noções são expressões das relações capitalísticas que, a todo momento e de diferentes formas, suscitam a produção de mecanismos de controle desses grupos populacionais na tentativa de torna-los empregáveis, utilizáveis e/ou rentáveis (TIENGO, 2016). Destacamos que algumas pesquisas se dedicam a estudar mais detalhadamente as relações da população de rua com os mundos do trabalho, em que este grupo populacional é considerado como "fruto da acumulação capitalista. Quanto maior for a acumulação de riquezas por poucos, maior será a acumulação de miséria” em diferentes grupos sociais. A acumulação de riquezas é colocada como um dos disparadores do processo de rualização de grupos e/ou indivíduos. Processo que está marcado "não por preguiça ou falta de esforço das pessoas, mas sim devido à natureza do modo de produção capitalista, que produz superpopulação relativa" (TIENGO, 2016: 19).

Ainda com relação aos mundos do trabalho, a maioria dos estudos capixabas enfatiza o trabalho informal como uma das principais táticas de existência da população de rua nos espaços urbanos. Para essas pesquisas, o trabalho informal caracteriza a população de rua como trabalhadora, contribuindo para colocar em análise as concepções clássicas de que este grupo social se define pela vagabundagem, pela inaptidão e pela mendicância. "A população em 
situação de rua encontra-se entre os trabalhadores informais tradicionais, em sua parcela mais instável possível, onde se exige baixa capitalização, gera uma renda baixa, voltada para subsistência, com a realização de trabalhos eventuais que exigem força física e baixa qualificação" (TIENGO, 2016: 120).

O trabalho informal designa aqui uma série de atividades, tais como realização de bicos, trabalho em pequenas jornadas e em empregos sazonais, catação de materiais recicláveis, produção de artesanato, guardar e lavar carros, auxiliar na montagem de barracas para feirantes, desembarque de mercadorias nos bares e mercados em determinadas regiões da cidade (KUNZ, 2012; ARAÚJO, 2014).

De fato, para alguns dos trabalhos que analisamos, é a possibilidade desse trabalho informal que faz da população de rua um fenômeno urbano, "visto que nas cidades há mais condições para a sua existência, assim como oferece uma arquitetura que lhe permita pernoitar, nelas estão os abrigos e albergues e as instituições de caridade e ONG's que oferecem alimentos nas ruas" (TIENGO, 2016: 118). No entanto, é possível observar nestes trabalhos uma reprodução da moralização das atividades que a população de rua realiza como tática de existência. É o que se nota quando tais produções se dedicam a justificar a relevância do trabalho informal para este grupo populacional em detrimento de outras atividades, pois ela estaria repleta de significados mais nobres para uma melhor valorização de si. Em outras palavras, "a utilização do trabalho informal serve para fugir da vergonha do desprezo social gerado pela mendicância, realizar sonhos, ter esperança, autovalorização (...) " (TIENGO, 2016: 10). Ou ainda, como aponta a mesma autora, "percebemos o destaque da própria subjetividade do trabalho informal. A realização do trabalho informal vem da necessidade imediata, material de sobreviver, mas também da valorização de si mesmo, está ligado à realização de sonhos e esperança de uma vida melhor" (TIENGO, 2016:118).

Alguns trabalhos realizados no Espírito Santo, no entanto, colocam em análise os modos de funcionamento das redes sociaoassistencias que teriam por objetivo atender as demandas da população em situação de rua em dado território. De fato, a questão que se coloca não é propriamente com relação às demandas dos usuários da rede, mas se o modo de gestão e a gama de serviços implementados no município de Vitória tem propiciado a saída das ruas de grupos e/ou indivíduos que desejem outra configuração de vida. Nesse sentido, tais produções acadêmicas questionam as políticas em termos de eficácia no sentido de apresentar e oferecer caminhos trilháveis para a saída das ruas, destacando a necessidade de políticas de moradia, de 
emprego e aluguel social, a garantia no acesso a direitos já constituídos, maior qualificação profissional para acompanhamento desses sujeitos (ARAÚJO, 2014). Alertas importantes são dados com relação aos efeitos que as atuais políticas têm sobre este grupo populacional, frequentemente realizando apenas a manutenção da precariedade de sua existência na cidade, sem de fato possibilitar um amplo acesso a garantia de direitos. É o que assinala Araújo ao dizer que “[...] a despeito da adequação às normas legais e às orientações técnicas da política de assistência social no País, bem como do comprometimento dos muitos trabalhadores da área, a atenção à população em situação de rua assume um caráter apenas de suporte às necessidades biológicas dessa população, limitando-lhe as possibilidades emancipatórias" (ARAÚJO,2014: 9).

Além disso, chamamos atenção para o foco dado às ações governamentais, argumentando que ainda são incipientes as ações que se realizam fora da esfera da assistência social, promovendo uma debilidade de políticas voltadas para outros âmbitos da vida, como educação, habitação, saúde, segurança alimentar, trabalho e geração de renda. Analisando as atividades desenvolvidas nos dispositivos assistenciais voltados para população de rua, ARAÚJO (2014) indaga a orientação das atividades ofertadas, visto que eram importantes para ocupar o tempo dos usuários (o que aparece, em muitos casos, com a tônica do trabalho realizado). De modo geral, a preocupação das unidades era manter ocupada a população nessa situação; no entanto, o senso prático da finalidade de determinadas atividades poderia constituir-se em elemento de rejeição, por não se perceberem as possibilidades de ganho ou a utilidade de determinadas tarefas, ou, ainda, por não se perceber sua real utilidade, vendo-as como mera ocupação do tempo livre (ARAÚJO, 2014: 126). Araújo ressalta ainda que muitas das ações implementadas, pensadas com o objetivo de reduzir os impactos estéticos da presença das pessoas em situação de rua na cidade, tinham como uma das estratégias guardá-las em serviços de acolhimento institucional e mantê-las ocupadas. Destacamos, junto com o autor, a importância das oportunidades de pensar em conjunto com os usuários as atividades que seriam realizadas. Atitude que muitas vezes é realizada principalmente para ampliar a adesão às proposições dos equipamentos públicos, e muito menos por entender que a população de rua deve ser escutada e dela é que devem partir os delineamentos das ações efetuadas.

Esses estudos também se indagam acerca das condições de permanência desses grupos e indivíduos em uma nova configuração de vida após a saída das ruas. No entanto, ressaltamos que esses trabalhos assumem a saída das ruas como única via de trabalho possível com a 
população em situação de rua, mais uma vez desconsiderando suas políticas de ocupação e deslocamento no território da urbe. Salientamos que estes trabalhos contribuem para um refinamento das políticas públicas já existentes e voltadas para este grupo populacional. Contudo, frequentemente ofuscam a multiplicidade dos sentidos do habitar suscitados pela população de rua pelo imperativo de saída das ruas, sem colocar em análise as próprias condições desse imperativo de saída/retirada. Em outras palavras, o que anteriormente se chamou por possibilidades emancipatórias entende-se por vezes apenas a possibilidade concreta de saída das ruas, e não a constituição de redes de atenção que trabalhem a garantia de direitos da população de rua desde os lugares que ela ocupa efetivamente na urbe.

Ainda no tocante à rede de serviços existentes, alguns estudos se debruçaram sobre a relação de determinados dispositivos no acompanhamento de crianças e adolescentes em situação de rua no município de Vitória, tais com o Centro de Referência Especializado em Assistência Social (CREAS) e o Centre de Referência em Assistência Social (CRAS). Tais pesquisa se realizaram por meio de encontros com profissionais dos serviços, como as crianças e adolescentes atendidos, a fim de explicitar a relação com os equipamentos da assistência e de suscitar neles novas modalidades de acolhimentos (GUARNIER, 2016). Percebe-se aqui que o cotidiano das crianças e adolescentes se constitui como um dos principais vetores de análise das políticas nacionais de atenção à infância e a adolescência. No entanto, a presença do cotidiano desses sujeitos muitas vezes se limita a indicar direitos violados, acessados, garantidos e necessários, sem abrir para uma análise das táticas que crianças e adolescentes criam não só para viverem nas ruas, mas, principalmente, para acessarem os serviços que de algum modo procuram regular esse cotidiano.

Ainda no âmbito das redes socioassistenciais, ressaltamos trabalhos que se dedicaram a construir uma pesquisa no entrecruzamento de diversas experimentações no campo da Assistência Social, tanto experiências de trabalho quanto em espaços de militância e participação popular. A pesquisa realizada por Lopes (2015) propõe discutir como vêm se efetuando atualmente os processos de resistências e os processos de regulamentação da vida a partir do Serviço de Proteção e de Atendimento Integral à Família (PAIF), desenvolvido no CRAS. Destacamos que o PAIF não tem por público alvo a população de rua; no entanto, o estudo tematiza em determinados aspectos a chamada situação de rua no âmbito dos dispositivos socioassistenciais. Tais pontos colocam em evidência determinadas noções que percorrem o campo da assistência social e que também contribuem para uma modelização da 
atenção voltada para grupos e indivíduos em situação de rua, tais como as noções de família, de higienização, de trabalho, de caridade/assistencialismo, da naturalização de risco e de vulnerabilidade atrelados a esse segmento populacional. A pesquisadora aponta ainda para uma série de práticas que extrapolam o âmbito restrito das políticas institucionalizadas em assistência social, configurando uma rede de práticas de generosidade, política de resistência e de rebeldias.

$\mathrm{Na}$ mesma direção, algumas produções acadêmicas no Espírito Santo procuram compreender como se constitui na região metropolitana a necessidade do poder público em instituir redes de atenção a população de rua. O que se percebe nesses estudos é o constante tensionamento entre as ocupações dos espaços urbanos realizadas pela população de rua e o projeto de uma cidade retilínea, que não ancora essa política da existência itinerante. Nas palavras de Kunz, vislumbra-se a emergência de "procedimentos que visam conter a mobilidade destes sujeitos nos espaços da cidade [como a construção de verdadeiras barricadas na cidade, por meio da instalação de cercas e grades nas praças e prédios], e garantir a ordem sob o manto da defesa de direitos de segurança de alguns" (KUNZ, 2012: 26).

Destacam-se aqui os procedimentos que têm por objetivo atenuar o tensionamento entre certa ordem urbana e a presença dita antissocial do morador de rua: fazer uso adequado de banheiros públicos, não utilizar bicas e chafariz para o banho, não cozinhar nas calçadas e praças, não deixar visíveis nas vias públicas seus pertences pessoais, incluindo colchões e cobertores entre outros utensílios, não ter publicamente contatos íntimos ou atitudes que pudessem incorrer como atentado ao pudor constam como orientações a serem feitas nas abordagens com o povo da rua

O cotidiano desse grupo populacional é assim o alvo privilegiado da intervenção desse projeto de cidade, em que a vida na rua é entendida como decorrente do uso problemático de álcool e outras drogas, uma vida matizada por gradações de estados patológicos, predisposições genéticas, caracterizando-a como doença a ser combatida por ações governamentais cada vez mais ostensivas (KUNZ, 2012; MARINS, 2013). Em outras palavras, uma série de práticas que têm por efeito criminalizar e patologizar o cotidiano da população de rua, transformando em virtualidades perigosas as existências inseparáveis das ruas. Nesse contexto, os moradores de rua são vistos como violentos e perigosos e essa constante dicotomia entre os bons e os maus pobres mostra-se presente em algumas produções acadêmicas analisadas neste estudo. 
Ainda acerca da constituição da rede de atenção a população de rua, a pesquisa realizada por Marins (2013) no município de Vitória evidencia como a demanda generalizada de retirada das ruas pautou as ações dos serviços que compõem a rede. $\mathrm{O}$ foco principal dessas ações, que ainda se fazem presentes nos serviços socioassistenciais, é o de retirar as pessoas das ruas e devolver ao convívio familiar. "À Assistente Social cabia a função de viabilizar o contato com os familiares dos acolhidos com o intuito de reencaminhá-los à convivência e cuidados familiares" (MARINS, 2013: 30). Essa modalidade de atenção tinha como um de seus objetivos ampliar a rotatividade de pessoas e/ou grupos na dependência de serviços como albergues e hospedagem noturna, possibilitando o acolhimento de novos assistidos, reduzindo assim a imensa fila de espera para as poucas vagas ainda hoje ofertadas pelos serviços. Entretanto, a indisponibilidade dos familiares nessa nova convivência acabou logo impossibilitando a rotatividade esperada inicialmente. Diante do exposto, o Governo do Estado do ES criara por sua vez um serviço de acolhimento institucional destinado a adultos em situação de rua com relação aos quais se haviam esgotado as possibilidades de reinserção familiar. A tutela dessas pessoas passa então para as mãos de Estado. A este respeito, escreve Marins (2013:30): “à medida que se constatava a impossibilidade de inclusão do adulto em situação de rua à lógica do comércio fervilhante da região central da capital, o Estado acabava por promover seu desaparecimento das cenas da cidade".

Atender à população de rua, na rua, nasce, portanto, como uma ação auxiliar, como um instrumento, um meio para se alcançar uma outra ação, que era a retirada das ruas, o acolhimento provisório e a reintegração familiar. Além disso, o que fica evidente aqui é que esse conjunto de políticas governamentais acaba por dificultar o acesso da população de rua à cidade. Essa demanda social de desocupação da população de rua das cenas da cidade acompanhou todo o desenvolvimento da política pública municipal no que se refere à atenção a esse público. Mais do que acompanhar, a demanda social parece ter produzido no poder público municipal todo um movimento de questionamentos, revisões e alterações nas estratégias de atuação junto à população adulta em situação de rua de Vitória. A demanda social de desocupação da população de rua do espaço urbano vai produzindo nas redes de atenção estratégias e técnicas diferentes e cada vez mais sofisticadas para promover a precarização e a inviabilização da presença da população de rua nas cenas da cidade (MARINS, 2013).

Expressão disso é a forma como a condição de rua aparece em alguns trabalhos como associada e, principalmente, reduzida a trajetórias de exclusão social, situações de 
vulnerabilidade e fragilização das relações familiares. A rua é também compreendida como espaço produtor de adoecimento mental, contribuindo para ofuscar a rua como espaço de embate político onde se efetuam histórias de resistências e de lutas por produção de saúde. A rua é tomada aqui como espaço natural da miséria, do adoecimento e do suposto alheamento político. Vale destacar que, em tais estudos, os movimentos nacionais e estaduais da população em situação de rua, tais como o Movimento Nacional da População de Rua (MNPR), o Movimento Nacional de Meninos e Meninas de Rua (MNMMR) e o Movimento Nacional de Catadores de Materiais Recicláveis (MNCR) não são mencionados. De acordo com esses trabalhos, quanto maior o tempo nas ruas, maior o agravamento físico e mental. São poucos os trabalhos que, além de apontar a existência dos movimentos, partem diretamente de suas movimentações na cidade para a construção de suas análises (KUNZ, 2012; ARAÚJO, 2014; JUNIOR, 2015).

Dessa maneira, os chamados processos de rualização, que levam as pessoas a utilizarem as ruas como espaço de moradia e sustento, frequentemente são apresentados como um conjunto de vetores que que exprimem uma progressiva destruição da vida social e psíquica (WANDEKOKEN, 2011). A vida na rua é narrada acentuando-se, principalmente, as carências, as faltas, as desagregações, a dependência química e as desordens comportamentais, tais como "a desvinculação familiar, o desemprego, a migração em busca de trabalho visando saída de uma vida com condições precárias, (...) utilização de álcool e outras drogas (...), falta de moradia, a vergonha do homem provedor em voltar para casa sem conseguir manter a sua família" (TIENGO, 2016: 17).

No âmbito da saúde, ressaltamos que recorrentemente os estudos que lidam com a população de rua como dependentes químicos contam apenas com os levantamentos realizados pelos serviços das redes de atenção em saúde e socioassistenciais a partir das fichas de acolhimento dos serviços. Destacamos que uma parcela considerável da população de rua na região metropolitana da Grande Vitória não é atendida por esses serviços. Outrossim, nenhum desses estudos realizou uma pesquisa mais apurada acerca das relações entre a situação de rua e o chamado uso problemático de álcool e outras drogas, tampouco colocou em análise o modo como se deu a produção dos dados informados pelas redes de serviços. É importante dizer também que não fica explicitado nesses estudos o que se entende por dependência química, uso abusivo ou mesmo uso de drogas, sendo essas três expressões muitas vezes tratadas como sinônimas. (WANDEKOKEN, 2011). Por outro lado, Araújo (2014) destaca que ao 
considerarmos a população de rua como heterogênea, ao construir e implementar a política de assistência e em saúde, é preciso levar em conta as especificidades, como, por exemplo, a situação de mulheres grávidas, de adultos com crianças e famílias nas ruas, de modo a não reiterar violações nem separar as pessoas de suas únicas referências de sociabilidade e afeto. É necessário acompanhar as formas de trabalho nas ruas, como, por exemplo, a condição de trabalho dos catadores de materiais recicláveis e dos guardadores de carros, entre outros, de modo a pensar alternativas de intervenção (ARAÚJO, 2014: 170).

Embora os trabalhos que abordam o uso de drogas por este segmento da população contribuam para preencher a lacuna de conhecimento existente, e a ressaltar a importância dos profissionais de saúde acessarem os usuários de drogas em situação de rua, eles acabam por desenvolver uma relação direta entre viver nas ruas, a mendicância e o consumo de drogas, sem avançar numa discussão mais apurada sobre a condição de precarização da existência que atinge a população em situação de rua (WANDEKOKEN, 2011). Além disso, os trabalhos em geral não mencionam que a partir das Portarias $n^{\circ} 122$ e no 123, ambas de 25 de janeiro de 2012, as equipes de Consultório de Rua, inicialmente ligadas à Coordenação Nacional de Saúde Mental, passaram a se chamar Consultório na Rua, integrando os serviços da atenção básica. Na mesma direção, poucos trabalhos apontam a importância de se pensar os cuidados em saúde de forma não tutelar nem hospitalocêntrica, desconsiderando experiências atuais na perspectiva de uma atenção itinerante e da redução de danos. Ressaltamos que o acesso da população de rua a determinadas políticas coloca como requisito a realização de tratamento para o chamado uso problemático de álcool e outras drogas. No entanto, não encontramos trabalhos que se dediquem a questionar e propor formas de atendimento à população de rua pautadas em sua política de deslocamentos pela cidade. Assim, acabam oferecendo a este grupo populacional modalidades de atendimento que não dialogam diretamente com suas demandas e possibilidades concretas de acesso aos serviços. Dessa maneira, afirmamos a importância do Consultório na Rua e das políticas de redução de danos na elaboração de propostas de atendimento às demandas apresentadas por este segmento social.

Para tal, é necessário indagar-se, no momento de elaboração e implementação dessas políticas, como intervir em uma realidade diversa e dinâmica sem cair no risco de produzir normalizações, adaptações, modelos e protocolos de atendimento engessados. Enfatizamos aqui as relações e as singularidades que se estabelecem e são construídas no encontro com a população em situação de rua; logo, a importância de debater as dificuldades de integração entre 
a política de assistência para a população em situação de rua e os serviços de saúde. Destacamos que a população em situação de rua tem dificuldades de acessar a rede de atenção básica, que geralmente consegue atendimento na urgência e emergência (KUNZ, 2012; MACERATA et al., 2014). Os meios tradicionais de acesso à saúde, como exigência de documentos, endereço, dentre outras coisas, dificulta o acesso pela população de rua - segmento populacional que ainda é estigmatizado por sua condição de higiene pessoal e vestimenta.

Mas, ainda que poucos artigos da área da saúde abordem tal questão, a intersetorialidade entre políticas públicas é referida como uma estratégia importante de produção de desprecarização da vida na rua e de acesso às políticas públicas (ARAÚJO, 2014). A intersetorialidade é entendida aqui como processos organizados e coletivos e ações deliberadas que pressupõem o respeito à diversidade e às particularidades dos atores envolvidos. Apontam ainda a dificuldade de acesso da população de rua a serviços públicos assistenciais, aos serviços de saúde mental, alegando que muitas vezes fica a cargo da assistência social iniciar a articulação com toda a rede de saúde, atuando também como referências para os usuários. Indicam grandes dificuldades na articulação intersetorial dos serviços.

Pudemos perceber que os modos de vida da população em situação de rua são, em grande parte, desqualificados e desconhecidos pelos pesquisadores. A maioria dos artigos que compreendem o universo da pesquisa que efetuamos parte do pressuposto de que a população em situação de rua é consequência da pauperização dos meios urbanos, do aumento populacional e do desemprego, da vulnerabilidade social. Associam políticas públicas à inclusão social, redução de iniquidades e desigualdades e erradicação da pobreza. Não obstante, ainda que em menor número, destacamos os trabalhos que procuram acompanhar os modos de vida da população de rua em determinados espaços urbanos, isto é, as táticas que este grupo populacional inventa na tessitura dos territórios que ocupa, buscando entender a experiência de vida nas ruas (KUNZ, 2012; CUNHA, 2015; LOPES, 2015; JUNIOR, 2015; GUARNIER, 2016). Tais trabalhos indicam a relevância das narrativas de história de vida em pesquisas com essa população, demonstrando a riqueza de informação e complexidade dessas narrativas, a despeito de sua aparente simplicidade e das suposições de pobreza cognitiva e linguística sobre a fala desses sujeitos. Reconhecem a rua enquanto espaço de moradia e produção de vida.

Cabe aqui sublinhar importantes lacunas presentes de maneira geral nos trabalhos encontrados. Ressaltamos que o estudo da violência contra este grupo populacional não foi tematizado pela produção acadêmica publicada nos últimos 06 anos no Espírito Santo. De 
maneira geral, as práticas de violência contra a população de rua foram rapidamente citadas ou circunscritas ao âmbito da violação de direitos. Outrossim, ainda que em menor número, os estudos que se dedicaram a acompanhar o cotidiano da população de rua em determinados espaços da cidade pouco evidenciaram quais são os corpos que hoje residem nas vias públicas. Ao apenas indicar que a população de rua é heterogênea, sem indicar os elementos dessa heterogeneidade, determinadas questões presentes no cotidiano da vida na rua são ofuscadas. De acordo com o Primeiro Censo Nacional Sobre População em Situação de Rua (BRASIL, 2009), realizado entre os anos de 2007 e 2008, a maioria das pessoas que vivem nas ruas hoje no país são homens (82\%), jovens (53\% entre 25 e 44 anos), pardos e negros $(39,1 \%$ dos entrevistados se declararam pardos e $27,9 \%$ negros), com baixo escolaridade e trabalhadores informais. Ao desconsiderar essas especificidades, notamos que os trabalhos encontrados não trazem em suas análises questões relacionadas ao racismo, à violência contra a juventude e à necessidade de políticas de produção de saúde para população negra. Ainda que o número de mulheres em situação de rua seja menor, e que uma estimativa acerca da população LGBT sequer seja apontada, nenhum dos trabalhos se dedica a debater questões relacionadas a gênero, a indagações acerca das especificidades em saúde da mulher em situação de rua, às condições de trabalho como profissionais do sexo, tanto para mulheres quanto para homens, e às formas de acolhimento institucional para pessoas LGBT's nos dispositivos de assistência.

Por fim, há que se destacar, por um lado, a reduzida produção de conhecimento acadêmico que toma questões voltadas à população em situação de rua como campo problemático e, de outro, o caráter de distanciamento e o desconhecimento que essa mesma produção do conhecimento no âmbito universitário tem dos saberes, das táticas, e das estratégias de existência produzidas por este grupo populacional na sua relação consigo e com os outros, com a cidade, com a políticas públicas e com os demais segmentos sociais que compõem a complexidade do tecido urbano.

\section{Referências}

ARAÚJO, Cristiano Luiz Ribeiro de. Gestão social da população em situação de rua na cidade de Vitória - ES - de 2005 a 2012. Dissertação de Mestrado. Universidade Federal do Espírito Santo, 2014.

BESSA, Décio. Cidadãos e cidadãs em situação de rua: uma análise de discurso crítico da questão social. Tese de Doutorado. Universidade de Brasília, Brasília, 2009. 
BRASIL. Ministério do Desenvolvimento Social e Combate à Fome. Secretaria de Avaliação e Gestão da Informação e Secretaria Nacional de Assistência Social. Rua: Aprendendo a Contar: Pesquisa Nacional sobre População em Situação de Rua. Brasília, 2009.

CORBIN, Alain. Saberes e odores: o olfato e o imaginário social nos séculos XVII e XIX. Trad, Lígia Watanabe. São Paulo: Companhia das Letras, 1987.

CUNHA, Juliana Gomes da. Pessoas em situação de rua e seus cães: fragmentos de união em histórias de fragmentação. Dissertação de Mestrado. Universidade Federal do Espírito Santo. 2015.

ESCOREL, Sarah. Vivendo de teimosos: moradores de rua da cidade do Rio de Janeiro. In: BURSZTYN, Marcel. (Org,). No meio da rua: nômades, excluídos e viradores. Rio de Janeiro: Garamond, 2000, pp.139-171.

FERREIRA, Norma Sandra de Almeida. As pesquisas denominadas "Estado da Arte". Revista Educação \& Sociedade, ano XXVIII, n. 79, 2002. 2008.

GIL, Antônio Carlos. Como elaborar projetos de pesquisa. 4. Ed. São Paulo: Atlas,

GUARNIER, Franciely da Costa. O Que As Crianças nos Ensinam em Suas Andanças Errantes Pelas Ruas da Cidade e Pelos Centros de Referência Especializados da Assistência Social. Dissertação de Mestrado. Universidade Federal do Espírito Santo, 2016.

HECKERT, Ana Lúcia Coelho.; PINHEIRO, Diego Arthur Lima; SABINO, Tuhany de Oliveira. População de rua e dispositivos de conversa: operadores de diferença nos centros urbanos. Em: Lima, E, R. (Org.). Cadernos de Agenciamentos. (pp.400-402) Salvador: UFBA, 2016. Recuperado em: http://www.corpocidade5.dan.ufba.br/index.php/caderno-deagenciamentos/

IPEA. Estimativa da população em situação de rua no Brasil. Brasília, 2016.

JUNIOR, Antônio Martins Vitor. Militâncias: andarilhando por territórios de vida. Universidade Federal do Espírito Santo. 2015.

KASPER, Christian Pierre. Habitar a rua. Tese de Doutorado. Universidade Estadual de Campinas, São Paulo, 2006.

KUNZ, Girlderlandia Silva. Os Modos de vida da População em Situação de Rua: narrativas de andanças nas ruas de Vitórias/ES. Dissertação de Mestrado. Universidade Federal do Espírito Santo, 2012.

KUNZ, Gilderlandia Silva.; HECKERT, Ana Lúcia Coelho; CARVALHO, Silvia Vasconcelos de. Modos de vida da população em situação de rua: inventando táticas nas ruas de Vitória/ES. Revista Fractal V. 26, n.3., 2014, pp. 919-942.

LIMA, Mário Hélio Trindade. Cidade de papelão: mocós, cachangas e malocas. Vitória, ES: EDUFES, 1998.

LOPES, Keli. Resistências e Controles no PAIF/CRAS: o desafio de desnaturalizar práticas e inventar novos possíveis. Dissertação de Mestrado. Universidade Federal do Espírito Santo, 2015.

MACERATA, Iacã.; SOARES, José Guilherme Neves; RAMOS, Julia Florêncio Carvalho. Apoio como cuidado de territórios existenciais: Atenção Básica e a rua. Interfaces, v.18. Botucatu, 2014, pp. 919-930. 
MARINS, Lívia Ferreira Cardoso. Os serviços de atenção (na rua) à população em situação de rua de Vitória: uma história contada em três tempos. Dissertação de Mestrado. Universidade Federal do Espírito Santo, 2013.

PINHEIRO, Diego Arthur Lima. Subjetividades em situação de rua: uma analítica do governo dos pobres. Tese de Doutorado. Universidade Federal Fluminense, 2017.

ROMANOWSKI, Joana Paula; ENS, Romilda Teodora. As pesquisas denominadas do tipo "Estado da Arte" em Educação. Diálogo Educacional. Curitiba, v. 6, n.19, p. 37-50, set/dez, 2006.

ROSA, Cleisa Moreno Maffei (Org.). População de Rua: Brasil e Canadá. São Paulo: Hucitec, 1995.

TEIXEIRA, Célia Regina. O "Estado da Arte": a concepção de avaliação educacional veiculada na produção acadêmica do Programa de pós-graduação em Educação: Currículo (1975 - 2000). Cadernos de Pós-Graduação - Educação. V.5, n.1,p.59 - 66. São Paulo, 2006.

TIENGO, Verônica Martins. População em situação de rua: o fruto necessário à reprodução capitalista e a funcionalidade do trabalho informal. Dissertação de Mestrado. Universidade Federal do Espírito Santo, 2016.

VIEIRA, Maria. Antonieta da Costa; BEZERRA, Eneida Maria Ramos; ROSA, Clesia. Moreno Maffei. (Orgs.). População de rua: quem [e, como vive, como é vista]. São Paulo: Hucitec, 2004.

WANDEKOKEN, Kallen Dettmann. Proposta de Sistematização da Assistência de Enfermagem ao Usuário de Crack: Desafios e Possibilidades. Dissertação de Mestrado. Universidade Federal do Espírito Santo, 2011.

Diego Arthur Lime Pinheiro Professor no Departamento de Ciências Humanas e Filosofia da Universidade Estadual de Feira de Santana (UEFS) E-mail institucional: dalpinheiro@uefs.br ORCID ID: https://orcid.org/0000-0003-2701-1482

Ana Lúcia Coelho Heckert Professora aposentada do Departamento de Psicologia da Universidade Federal do Espírito Santo (UFES) E-mail: anaheckert@ uol.com.br ORCID ID: https://orcid.org/0000-0002-0026-3674

Lucas Xavier Silva Psicólogo graduado pela Universidade Federal do Espírito Santo E-mail: lucas.xaviersilva@gmail.com ORCID ID: https://orcid.org/0000-0002-8416-2167

Lucas de Souza Lopes Psicólogo graduado pela Universidade Federal do Espírito Santo E-mail: lucas.lopes33@hotmail.com ORCID ID: https://orcid.org/0000-0002-6756-9934 